\title{
Community Pharmacist's Knowledge, Practice and Barrier towards Reporting of Adverse Drug Reactions in Dammam, Saudi Arabia: A Cross-Sectional Survey Based Study
}

\author{
Mohammad Daud Ali*, Ayaz Ahmad, Yousif Amin Mohamed Hassan, Sherihan Ahmed Ghosn, Nuzhat Banu, Mohammed Gharmullah \\ Alzahrani \\ Department of Pharmacy, Mohammad Al-Mana College for Medical Sciences, Abdulrazaq Bin Hammam Street, As Safa, Dammam, SAUDI ARABIA.
}

\begin{abstract}
Objectives: The current study aims to assess community pharmacist's knowledge, practice and barriers towards ADR reporting systems in the Dammam, Saudi Arabia. Methods: A cross-sectional study was conducted from $1^{\text {st }}$ August 2019 to $31^{\text {st }}$ October 2019 among the Community pharmacies in the Dammam, Saudi Arabia. 101 easily approachable community pharmacists participated in study. Results: The survey was sent to the 150 community pharmacists (CP), while only 101 surveys were received completely filled, the response rate of survey was $67.33 \%$. The mean age of the survey respondents were $35.2 \pm 6.66$ years. Among all the respondents $73(72.27 \%)$ were male and $28(27.73 \%)$ were female. Mean years of experience was $7.5 \pm 3.37$. Overall, 90 (89.1\%) respondents familiar with the term Pharmacovigilance $(p<0.05) .40(39.60 \%)$ community pharmacists agreed upon that they have sufficient knowledge and training on how to report ADRs $(p<0.05) .67(66.34 \%)$ respondents never reported new ADR (not mentioned in drug leaflet) for any drug $(p=0.001) .55(54.45 \%)$ respondents prevent different kind of serious ADRs during their practice $(p=0.370)$.
\end{abstract}

Conclusion: Community pharmacist working in Dammam were found to be unsatisfactory knowledge and practice on ADR reporting. The study also identified factors contribute in under reporting of ADR by community pharmacist. Drug regulatory agency and pharmacovigilance centres should take necessary steps to increase the awareness on ADR reporting among community pharmacist.

Key words: ADR (Adverse Drug Reaction), Community pharmacist, Dammam, Knowledge, Saudi Arabia.

Correspondence

Dr. Mohammad Daud Ali

Department of Pharmacy, Mohammed Al-Mana College for Medical Sciences, Abdulrazaq Bin Hammam Street, As Safa, Dammam-34222, SAUDI ARABIA.

Phone: +966 537018749

Email: dali.niper@gmail.com

DOI: 10.5530/jyp.2020.12.16

\section{INTRODUCTION}

Pharmacist job responsibility have been transmitted from traditional aspect of preparation and dispensing of medicines to more vital role that includes many aspects of pharmaceutical care, like stopping medication errors and ADRs, that may make satisfactory quality of life (QOL) and enlightening economic outcomes. ${ }^{1-3}$ Community pharmacists may play a key role in both pharmacovigilance related activities and ADRs reporting. ${ }^{4}$ Pharmacists are to be expected may identify more ADRs in comparison to other healthcare workers (HCWs), either in the community or hospital setting. ${ }^{5}$ Adverse drug reactions (ADRs) are usual reasons of mortality and morbidity in community as well as in hospital settings. In the current scenario $5 \%$ - $20 \%$ of hospital admissions are due to ADRs. ${ }^{6,7}$

Hence, post marketing surveillance (PMS) is obligatory for monitoring the risk and benefits of marketed pharmaceutical products. ${ }^{8}$ As a program to promote and monitor Adverse drug reaction (ADR) reporting, the Saudi Food and Drug Authority (SFDA) has reestablished a National Pharmacovigilance Center (NPC) that has made online reporting forms and papers forms available to encourage ADR reporting by healthcare workers and public. ${ }^{9}$

One study has been conducted in the Kingdom of Saudi Arabia (KSA) study reveals that lesser knowledge of the ADR reporting system and a poor reporting rate $(13.2 \%)$. Obstacles towards ADR reporting recognized by this study comprised, most commonly, a lack of awareness about where and how to report ADRs and unavailability of ADR reporting forms. ${ }^{10}$
Evaluation of knowledge, practice and experiences of community pharmacists towards spontaneous reporting of ADRs is highly significant. When pharmacists have adequate knowledge towards ADR reporting process, they can take part in improvement of other healthcare professional's knowledge regarding ADR reporting. ${ }^{11}$

In the Saudi Arabia several study have been conducted regarding estimation of community pharmacist's knowledge, attitude and practices for ADR reporting are inadequate and most of study were conducted before the establishment of the National Pharmacovigilance Centre. ${ }^{10}$ That's why, the objective of our research was to evaluate Community pharmacist's knowledge, perspectives and barrier in the reporting of adverse drug reactions in Dammam, Saudi Arabia after establishment of National Pharmacovigilance Centre.

\section{MATERIALS AND METHODS}

\section{Survey design and setting}

Study was performed amongst community pharmacist of Dammam, Saudi Arabia. Study was conducted by following descriptive cross sectional methods. Study was conducted for a period of 3 months from $1^{\text {st }}$ August 2019 to $31^{\text {st }}$ October 2019.

\section{Study tool}

A self-administered, 42-items questionnaire was used to record respondent's views about ADR reporting and their barriers to their 
reporting. The study questionnaire was adopted from previously published literature. ${ }^{10,12,13}$ The questionnaire was basically composed of three parts. First part comprised of ten items, mainly information related to the demographics and pharmacy and pharmacy practice associated information (Table 1 ). The $2^{\text {nd }}$ part of questionnaire comprised of thirteen questions of likert scale to measure community pharmacist's perception towards ADR reporting. The third part of the questionnaire consisted eight questions of close-ended question designed to estimate community pharmacist's practice regarding ADRs. The third part of the questionnaire consisted ten questions of likert scale to measure community pharmacist's barriers on ADR reporting. The link of survey (Google Forms) has been distributed through social media to the community pharmacist located in Dammam region, Saudi Arabia. After sending the link of survey prior to close the survey three reminders were also given to participate in survey.

\section{Study sample and data collection}

A total of 135 questionnaires link were distributed among community pharmacist of Dammam region though social media, of which only 101 participants answered the questionnaire.

\section{Ethical approval}

Study protocol has been approved from Scientific Research Unit Mohammed Al-Mana College for Medical Sciences with reference number: $\mathrm{SR} / \mathrm{RP} / 18$.Moreover, online consent was also requested from the study participants who wished to participate in the study.

\section{Data analysis}

Data analysis was performed using the Statistical Package for Social Science Version 22 (SPSS V.22) (Institute Inc: Cary, NC, USA). Demographic characteristics were applied to calculate the numbers (frequencies) and percentages; mean \pm standard deviation). Associated factors within group were calculated using the chi-square $\left(\chi^{2}\right)$ test. A $p$-value $\leq 0.05$ was considered statistically significant.

\section{RESULTS}

The survey was sent to the 150 community pharmacists, while only 101 surveys were received completely filled, there response rate of survey was $67.33 \%$. The mean age of the survey respondents were $35.2 \pm 6.66$ years. Among all the respondents $73(72.27 \%)$ respondents were male and $28(27.73 \%)$ respondents were female community pharmacist. Of all the community pharmacist answered questionnaire, 23(22.77\%) were Diploma, 55 (54.45\%) were Bachelor, 19(18.81\%) were Master and $4(3.96 \%)$ were $\mathrm{PhD}$. Mean years of experience was $7.5 \pm 3.37$. The average number of prescription dispensed per day by the community pharmacist were $39.89 \pm 15.86$ per day. While average time spent with patient were $7.5 \pm 3.37$ per minutes. Detailed information about the demographics are shown in Table 1.

\section{Community pharmacist's knowledge about the ADR reporting system in Saudi Arabia}

Knowledge regarding ADRs and their reporting was evaluated using the five items shown in Table 2. Overall, $90(89.1 \%)$ of the respondents familiar with the term Pharmacovigilance $(p<0.05) .40 \quad(39.60 \%)$ community pharmacists agreed upon that they have sufficient knowledge and training on how to report ADRs ( $p<0.05), 10(9.9 \%)$ strongly agree, $9(8.91 \%)$ disagree, $5(4.95 \%)$ strongly disagree and $37(36.63 \%)$ given their neutral response. $89(88.11 \%)$ respondents knows about availability of official and standard form for ADR reporting in Saudi Arabia $(p<0.05)$ while $12(11.89 \%)$ have no idea. $47(46.53 \%)$ respondents are strongly agree on, reporting Adverse Drug Reactions (ADRs) is important for
Table 1: Respondent's demographic characteristics of $(n=101)$ community pharmacists.

\begin{tabular}{|c|c|c|}
\hline Parameter & Number $(n=101)$ & $(\%)$ \\
\hline \multicolumn{3}{|l|}{$\begin{array}{c}\text { Age in Years } \\
{[\text { Mean } \pm \mathrm{SD}=35.2 \pm 6.66]}\end{array}$} \\
\hline $20-30$ & 23 & 22.77 \\
\hline $31-40$ & 59 & 58.41 \\
\hline $41-50$ & 18 & 17.83 \\
\hline 50 and above & 1 & 0.99 \\
\hline \multicolumn{3}{|l|}{ Gender } \\
\hline Male & 73 & 72.27 \\
\hline Female & 28 & 27.73 \\
\hline \multicolumn{3}{|l|}{ Graduation year from pharmacy college } \\
\hline$<5$ Years & 28 & 27.73 \\
\hline $5-10$ years & 37 & 36.63 \\
\hline$>10$ years & 36 & 35.64 \\
\hline \multicolumn{3}{|l|}{ Highest level of pharmacy qualification } \\
\hline Diploma & 23 & 22.77 \\
\hline Bachelor & 55 & 54.45 \\
\hline Master & 19 & 18.81 \\
\hline $\mathrm{PhD}$ & 4 & 3.96 \\
\hline \multicolumn{3}{|l|}{$\begin{array}{c}\text { Experience years Age in Years }[\text { Mean } \pm \text { SD } \\
=7.5 \pm 3.37]\end{array}$} \\
\hline 5 years or less & 23 & 22.77 \\
\hline 6-9 years & 39 & 38.61 \\
\hline 10 years or more & 39 & 38.61 \\
\hline \multicolumn{3}{|l|}{$\begin{array}{l}\text { Number of prescription dispensed per } \\
\quad \text { day }[\text { Mean } \pm S D=39.89 \pm 15.86]\end{array}$} \\
\hline$<30$ & 31 & 30.69 \\
\hline $31-50$ & 37 & 36.63 \\
\hline$>50$ & 33 & 32.67 \\
\hline \multicolumn{3}{|l|}{$\begin{array}{l}\text { Time spent with patient }[\text { Mean } \pm \mathrm{SD}= \\
7.5 \pm 3.37]\end{array}$} \\
\hline$<5$ Min & 47 & 46.53 \\
\hline $6-10 \mathrm{~min}$ & 46 & 45.54 \\
\hline$>10 \mathrm{~min}$ & 8 & 7.92 \\
\hline \multicolumn{3}{|l|}{ Hours worked per week } \\
\hline$<20 \mathrm{hr}$ & 10 & 9.90 \\
\hline $21-40 \mathrm{hr}$ & 39 & 38.61 \\
\hline$>40 \mathrm{hr}$ & 52 & 51.48 \\
\hline
\end{tabular}

patient care $(p<0.05)$ while $27(26.73 \%)$ are agree, $4(3.96 \%)$ strongly disagree, 2(1.98\%) disagree and 21(20.79\%) respondents given their neutral response. Among all study participants 38(37.62\%) were agreed upon, reporting of ADRs should be mandatory for community pharmacists $(p<0.05)$ while $25(24.75 \%)$ strongly agree, $8(7.92 \%)$ strongly disagree, $3(2.97 \%)$ disagree and $27(26.73 \%)$ are neutral. 
Table 2: Responses to the knowledge related questions.

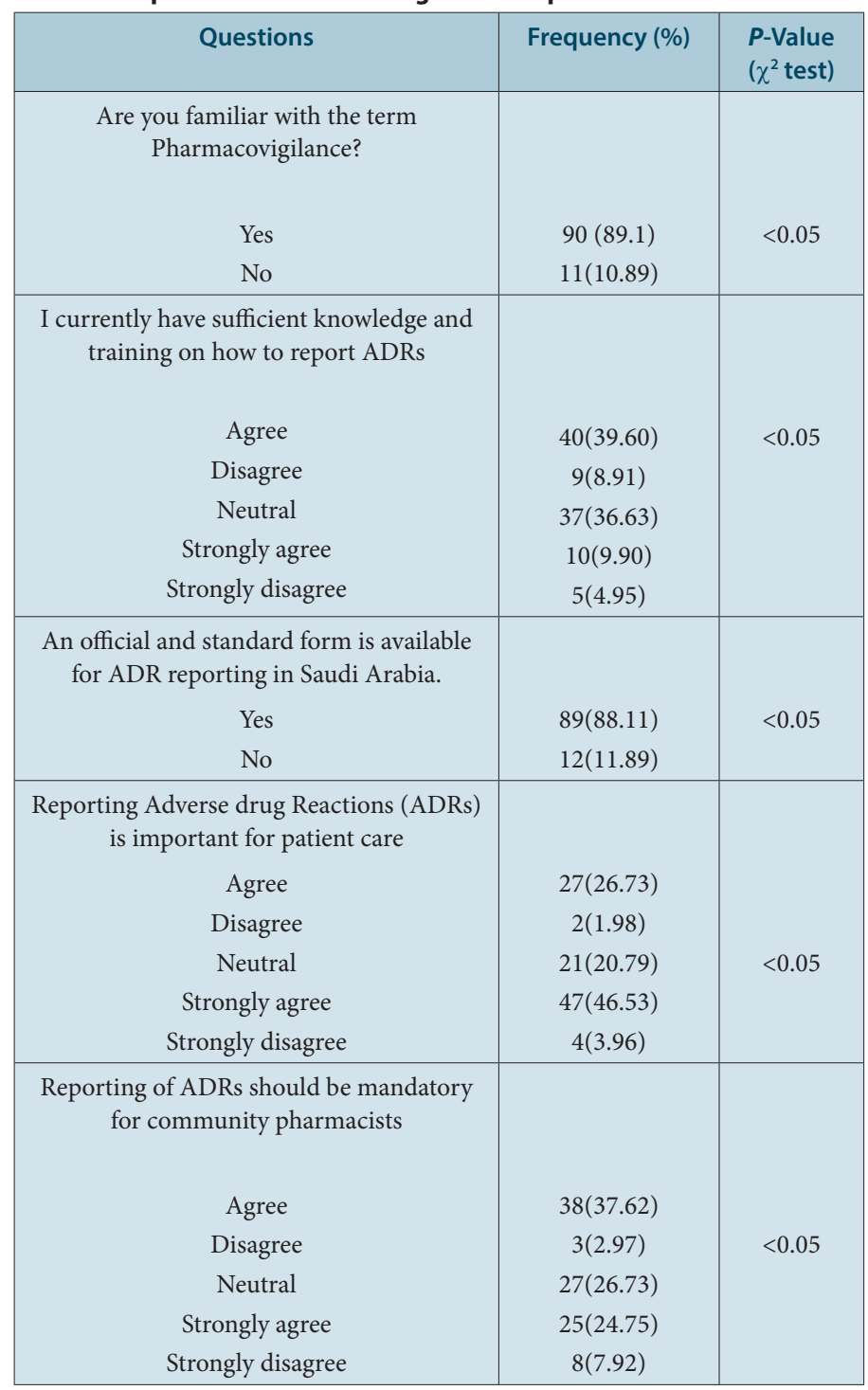

${ }^{*}$ Significant $p$-value $(<0.05)$

\section{Community pharmacists' practice about the ADR reporting in Saudi Arabia}

The details of community pharmacist practice regarding ADR reporting has been listed in Table 3. 53(52.47\%) of the respondents notice any ADRs by the use of medicine within the last 12 months $(p=0.618)$. $44(43.56 \%)$ of the respondents sent a suspected ADR report to Saudi Food and Drug Authority (SFDA) or manufacturer during their practice $(p=0.195)$. Only $37(36.63 \%)$ of the respondents ever reported any ADRs related to OTC or herbal products in the last 12 months $(p=0.007)$. $67(66.34 \%)$ of the respondents never reported new ADR (not mentioned in drug leaflet) for any drug ( $p=0.001) .55(54.45 \%)$ of the respondents prevent any serious ADRs during their practice $(p=0.370)$. In addition $61(60.39 \%)$ of the respondents read an article related to ADRs in the last 12 months $(p=0.036) .62(61.38 \%)$ of the respondents involved in counselling of the patient regarding ADRs in the last 12 months $(p=0.022)$. Overall 77(76.23\%) of the respondents are involved in counselling of the patient regarding food/drug interaction in the last 12 months $(p=0.00)$. Overall 66(65.35\%) of the respondents don't have private patient counselling room in their pharmacy $(p=0.002)$. $70(69.30 \%)$ of the
Table 3: Community pharmacist practice regarding ADRs reporting in Saudi Arabia.

\begin{tabular}{|c|c|c|c|}
\hline Questions & Yes (\%) & No (\%) & $\begin{array}{l}P \text {-Value } \\
\left(\chi^{2} \text { test }\right)\end{array}$ \\
\hline $\begin{array}{l}\text { Have you notice any ADRs within } \\
\text { the last } 12 \text { months? }\end{array}$ & $53(52.47)$ & $48(47.52)$ & 0.618 \\
\hline $\begin{array}{l}\text { Have you ever sent a suspected ADR } \\
\text { report to SFDA or manufacturer? }\end{array}$ & $44(43.56)$ & $57(56.43)$ & 0.195 \\
\hline $\begin{array}{l}\text { Have you ever reported any ADRs } \\
\text { related to OTC or herbal products in } \\
\text { the last } 12 \text { months? }\end{array}$ & $37(36.63)$ & $64(63.37)$ & 0.007 \\
\hline $\begin{array}{l}\text { Have you ever reported a new ADR } \\
\text { (not mentioned in drug leaflet) for } \\
\text { any drug? }\end{array}$ & $34(33.66)$ & $67(66.34)$ & $0.001^{\star}$ \\
\hline $\begin{array}{l}\text { Have you ever prevent any serious } \\
\text { ADRs? }\end{array}$ & $55(54.45)$ & $46(45.55)$ & 0.370 \\
\hline $\begin{array}{l}\text { Have you read an article related to } \\
\text { ADRs in the last } 12 \text { months? }\end{array}$ & $61(60.39)$ & $40(39.60)$ & $0.036^{\star}$ \\
\hline $\begin{array}{l}\text { Have you ever counselled patient } \\
\text { regarding ADRs in the last } 12 \\
\text { months? }\end{array}$ & $62(61.38)$ & $39(38.62)$ & $0.022^{\star}$ \\
\hline $\begin{array}{l}\text { Have you ever counselled patient } \\
\text { regarding food /drug interaction in } \\
\text { the last } 12 \text { months? }\end{array}$ & $77(76.23)$ & $24(23.76)$ & $0.00^{*}$ \\
\hline $\begin{array}{l}\text { Do you have private patient in } \\
\text { counselling room in your pharmacy? }\end{array}$ & $35(34.65)$ & $66(65.35)$ & $0.002^{\star}$ \\
\hline $\begin{array}{l}\text { Do you have pharmacy technician in } \\
\text { your pharmacy? }\end{array}$ & $70(69.30)$ & $31(30.69)$ & $0.001^{*}$ \\
\hline $\begin{array}{l}\text { Do you have automation facility in } \\
\text { your pharmacy? }\end{array}$ & $51(50.49)$ & $50(49.50)$ & 0.920 \\
\hline
\end{tabular}

* Significant $p$-value $(<0.05)$

respondents have pharmacy technician in their pharmacy $(p=0.001)$ while nearly half, 51 (50.49\%) of the respondents agreed that they automation facility in their pharmacy $(p=0.920)$.

\section{Community Pharmacist barriers toward reporting of ADRs}

The second last section of the study focused on exploring the barriers toward ADR reporting in Eastern province, Saudi Arabia. Community pharmacists have a professional obligation to report ADRs was the first barrier towards ADR reporting $(p=<0.05)$. Other barriers were the lack of time to report ADRs as part of their professional practice $(p=0.003)$. Other factors are shown in Table 4.

\section{Factors encouraging toward reporting of ADRs}

The last part of the questionnaires in the current study was about the facilitators that might motivate/encourage frequency to report an ADR. $41(40.59 \%)$ respondents suggested that community pharmacist would be stimulated to report more ADRs if general education is provided on the importance of pharmacovigilance. Rest of facilitators are shown in Figure 1.

\section{DISCUSSION}

We did this survey based study to investigate knowledge, practice, barrier and recommendation towards ADR reporting and its system amongst the community pharmacist of Dammam region, Saudi Arabia. Our study results displays that community pharmacists have insufficient knowledge 
Table 4: Barriers toward reporting of ADRs.

\begin{tabular}{|c|c|c|c|c|c|c|}
\hline Questionnaire & Agree (\%) & $\begin{array}{c}\text { Disagree } \\
(\%)\end{array}$ & $\begin{array}{c}\text { Neutral } \\
(\%)\end{array}$ & $\begin{array}{l}\text { Strongly } \\
\text { agree (\%) }\end{array}$ & $\begin{array}{c}\text { Strongly } \\
\text { disagree } \\
(\%)\end{array}$ & $\begin{array}{l}\text { P-Value } \\
\text { ( } X^{2} \text { test) }\end{array}$ \\
\hline I don't have the time to report ADRs as part of my professional practice & $28(27.72)$ & $19(18.81)$ & $32(31.68)$ & $6(5.94)$ & $16(15.84)$ & 0.003 \\
\hline I fear that there may be legal repercussions if I report an ADR to the SFDA & $23(22.72)$ & $14(13.86)$ & $46(45.54)$ & $4(3.96)$ & $14(13.86)$ & $<0.05$ \\
\hline I have a professional obligation to report ADRs & $36(35.64)$ & 15(14.85) & $35(34.65)$ & $12(11.88)$ & $3(2.97)$ & $<0.05$ \\
\hline There are no results or actions taken based on ADRs that I report & 21(20.79) & $17(16.83)$ & $47(46.53)$ & $3(2.97)$ & $13(12.87)$ & $<0.05$ \\
\hline Reporting forms are not available & $23(22.72)$ & $20(19.80)$ & $34(33.66)$ & $4(3.96)$ & $20(19.80)$ & 0.001 \\
\hline Reporting forms are too complicated & $22(21.78)$ & $14(13.86)$ & $46(45.54)$ & $2(1.98)$ & $17(16.83)$ & $<0.05$ \\
\hline Reporting is time consuming & $25(24.75)$ & $14(13.86)$ & $43(42.57)$ & $5(4.95)$ & $14(13.86)$ & $<0.05$ \\
\hline I fear legal liability of the reported ADR & $18(17.82)$ & $13(12.87)$ & $48(47.52)$ & $6(5.94)$ & $16(15.84)$ & $<0.05$ \\
\hline I am not motivated to report & $18(17.82)$ & $24(23.76)$ & $34(33.66)$ & $3(2.97)$ & $22(21.78)$ & $<0.05$ \\
\hline I am not confident whether it is an ADR & $20(19.80)$ & $22(21.78)$ & $40(39.60)$ & 2(1.98) & $17(16.83)$ & $<0.05$ \\
\hline Insufficient knowledge of pharmacotherapy in detecting ADR & $20(19.80)$ & $21(20.79)$ & $40(39.60)$ & $7(6.93)$ & $13(12.87)$ & $<0.05$ \\
\hline Unavailability of professional environment to discuss ADR & $26(25.74)$ & $13(12.87)$ & $43(42.57)$ & $8(7.92)$ & $11(10.89)$ & $<0.05$ \\
\hline
\end{tabular}

* Significant $p$-value $(<0.05)$

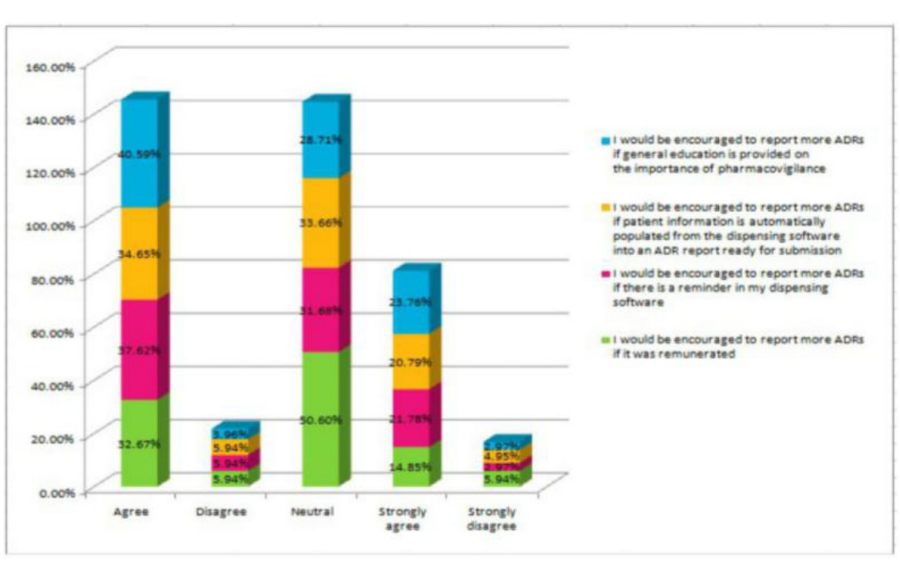

Figure 1: Responses to the recommendation towards reporting of ADRs.

regarding ADR reporting, few community pharmacists have reported $\mathrm{ADR}$ and the majority are aware of the process of ADR reporting. The findings of current study are nearer to previous studies conducted in the Riyadh, Saudi Arabia. ${ }^{10}$ Only 50.0\% community pharmacists have sufficient knowledge and training on how to report ADR in Saudi Arabia. The main reason for this might be the lack of encourage and facilities on ADR reporting in community pharmacy services. Moreover, community pharmacy in Saudi Arabia is knowingly business directed.

Thus, the concept of facilities and reporting of ADRs might be observed as a second priority by pharmacy tycoons. However, globally, community pharmacists in Australia, Nigeria and the UAE were not aware of the ADR reporting programs in their countries. ${ }^{14-16}$ In addition to awareness among community pharmacists, the role of regulatory authorities is also questionable due to the lack of implementation of regulations in community pharmacy practice. ${ }^{10}$ The survey included community pharmacist's from one city in Saudi Arabia which limits its generalization. In the current study, some pharmacists indicated that they have enough facility in their pharmacy, this may be moderately time spent on to the underreporting of ADRs. Also, community pharmacist's heavy workload might have limited the response rate. Although there is a reporting system in Saudi Arabia that deals with ADRs in both paper and electronic format, all ADR must send to SFDA or manufacturer the majority of community pharmacists are unaware of where to send ADR. The entire respondents in survey agreed that ADR reporting is important for patient care in community pharmacies. Operative ADR reporting systems in community pharmacies are a necessary element in any healthcare setup. Addition of PV topics in the curriculum of pharmacy education and training of pharmacy students in community pharmacy as internship may increase the wakefulness of upcoming pharmacists regarding ADR monitoring, detection and reporting. ${ }^{17}$ Moreover, pharmacy proprietors could allow the excess of internet and software facility in community pharmacies for online ADR reporting to drug regulatory authority.

\section{CONCLUSION}

Community pharmacist working in Dammam, Saudi Arabia were noticed having unsatisfactory knowledge and practice on ADR reporting. The study also identified factors contribute in under reporting of ADR by community pharmacist. Drug regulatory agency and pharmacovigilance centres should take obligatory steps to straightway and design interventional programs in order to accelerate the cognition and consciousness of community pharmacist's towards the reporting procedure of the ADR. A multiple shareholders approach can also foster ADR reporting as well as helps in development of huge awareness among community pharmacist.

\section{ACKNOWLEDGEMENT}

Authors acknowledge all the community pharmacist of Dammam who participated in this study.

\section{CONFLICT OF INTEREST}

The authors declare no conflict of interests.

\section{ABBREVIATIONS}

ADR: Adverse Drug Reaction; CP: Community pharmacists; QOL: Quality of Life; HCWs: Healthcare Workers; PMS: Post Marketing Surveillance; SFDA: Saudi Food and Drug Authority; NPC: National Pharmacovigilance Centre; KSA: Kingdom of Saudi Arabia.

\section{REFERENCES}

1. Kane S, Weber R, Dasta J. The impact of critical care pharmacists on enhancing 
patient outcomes. Intens Care Med. 2003;29(5):691-8.

2. Sears $E$, Generali J. Adverse drug reaction and medication error reporting by pharmacy students. Ann Pharmacother. 2005;39(3):452-9.

3. Grootheest AV, DeJong-van DBL. The role of hospital and community pharmacists in pharmacovigilance. Res Soc Adm Pharm. 2005;1(1):126-33.

4. Rajanandh MG, Praveen KV, Yuva SS. Roles of Pharmacist in Pharmacovigilance: A Need of the Hour. J Pharmacovigil. 2016;4(6):221.

5. Mohammad DA, Yousif AH, Ayaz A, Orjwan A, Al-Harbi H, Nada MA, et al. Knowledge, Practice and Attitudes toward Pharmacovigilance and Adverse Drug Reactions Reporting Process among Health Care Providers in Dammam, Saudi Arabia. Curr Drug Saf. 2018;13(1):21-5.

6. Lazarou J, Pomeranz BH, Corey PN. Incidence of adverse drug reactions in hospitalized patients: A meta-analysis of prospective studies. JAMA 1998;279(15):1200-5.

7. Pirmohamed M, James S, Meakin S. Adverse drug reactions as cause of admission to hospital: Prospective analysis of 18820 patients. $\mathrm{Br}$ Med J. 2004;329(7456):15.

8. Edlavitch SA. Postmarketing surveillance methodologies. Drug Intell Clin Pharm. 1988;22(1):68-78.

9. National Pharmacovigilance Centre. Saudi Food and Durg Authority. 2019 http:// www.sfda.gov.sa/En/Drug/Topics/Organogram/Pharmacovigilance/.

10. Bawazir SA. Attitude of community pharmacists in Saudi Arabia towards adverse drug reaction reporting. Saudi Pharm J. 2006;14(1):75-83.
11. Khalili H, Mohebbi N, Hendoiee N, Keshtkar AA, Dashti-Khavidaki S. Improvement of knowledge, attitude and perception of healthcare workers about ADR, a pre- and postclinical pharmacists' interventional study. BMJ Open. 2012;2(1):e000367.

12. Grootheest ACV, Puijenbroek EPV, DeJongvan BLTW. Contribution of pharmacists to the reporting of adverse drug reactions. Pharmacoepidemiol Drug Saf. 2002;11(3):205-10

13. Tahir M. Khan, Community pharmacists' knowledge and perceptions about adverse drug reactions and barriers towards their reporting in Eastern region, Alahsa, Saudi Arabia. Ther Adv Drug Saf. 2013;4(2):45-51.

14. Li R, Curtain C, Bereznicki L, Zaidi STR. Community pharmacists' knowledge and perspectives of reporting adverse drug reactions in Australia: A crosssectional survey. Int J Clin Pharm. 2018;40(4):878-89.

15. Adisa R, Adeniyi OR, Fakeye TO. Knowledge, awareness, perception and reporting of experienced adverse drug reactions among outpatients in Nigeria. Int J Clin Pharm. 2019;41(4):1062-73.

16. Alnajjar MS, Zamzoum LM, Saeed DA. Barriers to adverse drug reaction reporting in community practice in the UAE. J Pharm Health Serv Res. 2019;10(3):373-80

17. Christensen ST, Søndergaard B, Honore PH, Bjerrum OJ. Pharmacy student driven detection of adverse drug reactions in the community pharmacy setting. Pharmacoepidemiol Drug Saf. 2011;20(4):399-404.

Article History: Submission Date :23-01-2020 ; Revised Date : 15-02-2020 ;Acceptance Date : 29-02-2020

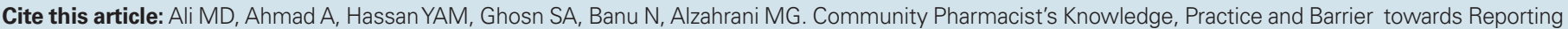
of Adverse Drug Reactions in Dammam, Saudi Arabia: A Cross-Sectional Survey Based Study. J Young Pharm. 2020;12(1):81-5. 